\title{
Apresentação do Volume 11 Número 22 da Revista Brasileira de História \& Ciências Sociais
}

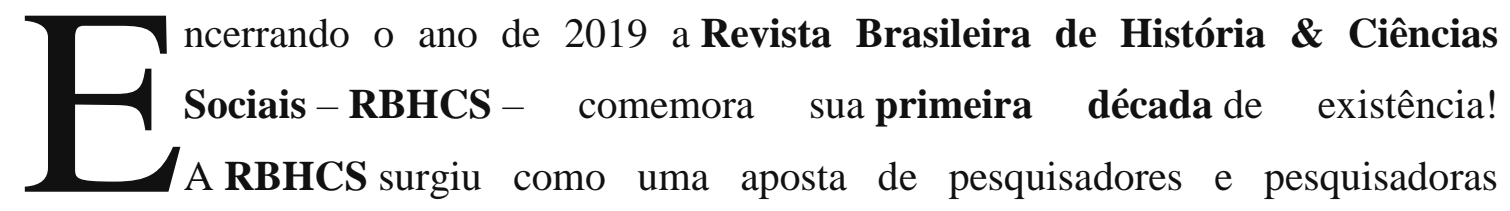
interessados em assuntos transversais entre a História e os diversos seguimentos das Ciências Sociais. A proposta que tomou corpo é de que, cada qual, dentro das especificidades de suas áreas, pudesse trazer elementos importantes para contribuição de determinados temas em comum.

Nesse ano, outra novidade, a RBHCS agora está vinculada e hospedada na base de periódicos da Universidade Federal de Rio Grande (FURG) com novo endereço (https://periodicos.furg.br/rbhcs). Salientamos que toda a base de dados já foi transferida e não alterou em nada as publicações anteriores dos últimos 10 anos de existência do periódico, ou seja, tudo foi mantido da mesma forma, inclusive os cadastros de acesso à plataforma.

E para brindar essa trajetória de muito esforço por parte de seus editores, a RBHCS em sua nova edição apresenta o dossiê "Gênero e números: estudos sobre as mulheres em diferentestempos e espaços", organizado pela Prof ${ }^{\mathrm{a}}$. Dr ${ }^{\mathrm{a}}$. Ana Silvia Volpi Scott e pela Prof ${ }^{a}$. Dr ${ }^{a}$. Denize Terezinha Leal Freitas. Trata-se de um tema pertinente e sensível ao nosso presente, uma contribuição de extrema importância que atravessa diversas áreas das Ciências Humanas.

Além do dossiê destacado, a atual edição apresenta diversos artigos também na sessão de temática livre e uma resenha. Frente a essa diversidade, a presente edição atinge a meta de nosso escopo editorial, mantendo-se um periódico multidisciplinar, que busca fomentar o diálogo às diversas áreas do conhecimento com base na teoria social.

Boa leitura a todos e todas!

Verão de 2019 
Editores da RBHCS

Profa. Denize Terezinha Leal Freitas (UNIPAMPA/SEDUC)

Prof. Fabiano Quadros Rückert (UFMS)

Prof. José Carlos da Silva Cardozo (FURG)

Prof. Jonathan Fachini da Silva (UFPEL/SMEC)

Prof. Tiago da Silva Cesar (UNICAP) 